\title{
50 anos e os 5 e-princípios da ciência da informação eletrônica*
}

Desejar um feliz 50ํaniversário, um feliz meio século ao Ibict e à comunidade brasileira de ciência da informação é, para mim, um prazer e uma honra.

Prazer de congratular uma instituição e uma revista que trabalharam para defender e tornar ilustre a ciência da informação brasileira.

Fico honrado por sua comunidade me considerar como um dos seus, fazendo minha voz ser ouvida em português do Brasil (ela é ouvida também em romeno de alguns meses para cá!), e também honrado por lhes escrever de novo, desta vez um editorial. Isto significa que, por um instante, torno-me editor de sua revista, e vocês me dão o privilégio de produzir um artigo de orientação geral. Esta pequena peça de literatura, eu não a farei de modo inofensivo. Editar em ciência significa expressar o que pensamos ser um devir para uma ciência, é encorajar as revoluções científicas, as rupturas que anunciam dias melhores, sociedades melhores, para o bem-estar dos praticantes desta ciência, isto é, encorajar o progresso científico.

\section{INTRODUÇÃO}

Para seus 50 anos, encontram-se, neste editorial, cinco presentes epistemológicos sob forma do que chamamos princípios científicos diretores, característicos dos novos paradigmas informacionais que estão em curso atualmente na ciência e na tecnologia da informação eletrônica: o princípio produtivista, o princípio interacionista, o princípio consumerista, o princípio métrico e o princípio eletrodigital.

Não podemos deixar de constatar que estamos diante de uma ciência e de uma tecnologia desenfreadas, turbulentas. Em conseqüência, devemos dominar um conjunto explosivo, em número e em variedade, de conhecimentos científicos e técnicos, que se caracteriza por:

- um surgimento ininterrupto de conceitos, métodos, modelos, leis etc.;

- um crescimento exponencial da largura de banda, da capacidade de memória, dos fluxos de tratamento automático de dados etc.
O conhecimento verdadeiro, como dizia Descartes, deve começar pela busca de princípios (os conhecimentos primários) e, depois, deles, deduzir certezas. O que ele reprovava, nas disciplinas que lhe haviam sido ensinadas, era o fato de não se apoiarem em fundamentos sólidos e de se limitarem ao provável. Conhecemos o importante papel dos princípios que orientam o pensamento científico, o qual necessita, nos diferentes domínios em que atua, de princípios diretores que orientem as pesquisas e que unifiquem as teorias, para o pior ou para o melhor. Estas orientações tão gerais do pensamento científico, que constituem um fermento gerador de descobertas, podem se constituir, com o passar do tempo, em um obstáculo ao seu desenvolvimento. De maneira geral, estes princípios são representações mais ou menos metafóricas de um conjunto de fenômenos. Mas, atenção, se a analogia continua a ser um conceito interdisciplinar fecundo que facilita o deslocamento de idéias de um domínio a outro, ela pode também bloquear, durante um longo período, a inteligência de um fenômeno. Assim, a analogia de irrigação na fisiologia bloqueou, por muito tempo, o progresso da inteligência da circulação do sangue. Da mesma forma, acreditamos que a analogia da transmissão de sinal elétrico, utilizada cegamente pelas ciências sociais e humanas, impediu, nas áreas de comunicação e de ciência da informação, o progresso da inteligência da comunicação da informação, fenômeno social e humano por excelência.

\section{I - O PRINCÍPIO PRODUTIVISTA (E-CONSTRUÇÃO)}

O advento da eletrônica, que se manifestou inicialmente pela passagem de suportes tradicionais, papéis, filmes etc. para suportes eletromagnéticos e optoeletrônicos, e, posteriormente, o desenvolvimento da informática e da transmissão a distância de sinais elétricos portadores de informação (telecomunicações) reforçaram as tendências produtivistas em matéria de informação. Além disso, a profissionalização generalizada da pesquisa, tanto acadêmica quanto industrial, conduziu, como sabemos, homens e mulheres (elas são ainda em menor número) que se dedicam à pesquisa a esperar da universidade ou da empresa não somente status, mas também remuneração, de maneira direta para os pesquisadores da indústria e de maneira indireta para os pesquisadores da universidade.

\footnotetext{
* Tradução de Marisa Bräscher - doutora em Ciência da Informação -
} professora da UnB e ex-diretora do IBICT 
Esta é uma causa aguda de desordem, na medida em que a publicação de um artigo deixou de ter por objetivo a consagração e se tornou imperativo fundamental para obter ou conservar um emprego.

Então, o que dizer da qualidade? Para avaliá-la, recorrese às citações. A julgar pelo pequeno número de citações recebidas pelos artigos (mais de 60\% nunca são citados), grande número de publicações de pouca qualidade é produzido. Para impedir esta superprodução de má qualidade, J.D. Bernal propôs, em 1948, a abolição das revistas científicas e o estabelecimento de uma distribuição centralizada de artigos (precursora dos bancos de prépublicações). Esta idéia provocou reações hostis por parte das sociedades científicas e dos editores que conseguiram impedir sua apresentação durante uma conferência. Ele, entretanto, errou também por ter tomado partido do campo socialista, no início da Guerra Fria! Mais recentemente, J.C. Gardin falava de superprodução das publicações em ciências humanas. Não será hora, então, de encontrar, graças à vitalidade do suporte eletrônico, soluções para este conhecido dilema? De reintroduzir o que os procedimentos de controle, de codificação, extinguiram quase que totalmente, isto é, as controvérsias científicas? O artigo, tornado público sob a responsabilidade total de seu(s) autor(es), pode ser objeto de um debate que o autor concluirá quando a controvérsia tiver terminado. $\mathrm{O}(\mathrm{s})$ autor(es) (ou a(s) autora(s)), então, poderão decidir quanto ao seu arquivamento ou não, isto é, quanto à publicação definitiva do artigo.

\section{II - O PRINCÍPIO INTERACIONISTA (E-COMUNICAÇÃO)}

As comunidades científicas e profissionais são, acima de tudo, redes de organizações e de relações sociais formais e informais que cumprem diversas funções. Uma das funções dominantes é a comunicação.

Infelizmente, cometemos um erro conceitual, na ciência da comunicação (e também na ciência da informação), que consiste em considerar o conceito de "informação", da teoria matemática da transmissão de sinais elétricos, análogo ao conceito de informação, no contexto do processo de comunicação humana.

Seguindo os passos de Shannon e Weaver, toda a comunidade das áreas de informação e de comunicação foi vítima ou cúmplice de um erro gerado por esta analogia. Aplicamos, então, as regras do modo de transmissão de sinais elétricos às comunicações humanas, que, desta maneira, só podem se tornar autoritárias e unidirecionais. O modelo resultante, amplamente difundido e ensinado, em particular nas escolas de jornalismo e nos departamentos de comunicação das universidades, coloca em jogo um "emissor" que "comunica" uma mensagem ao "receptor". Só há um que fala, os demais são "um bando de mudos", segundo Bateson. Jornais, televisão, rádio, todas as mídias ditas "de massa" (ou, mais exatamente, para influenciar as massas) funcionam segundo este modelo, com a teoria da comunicação de massa tentando explicar a distribuição de informação ao público sob influência das mídias e dos mediadores, os jornalistas. Este modelo atenuado (pois não há ainda publicidade) está seguramente em uso no setor de documentação, bibliotecas, museus e arquivos.

Isto se aplica bem menos à Internet. $\mathrm{O}$ desenvolvimento do correio eletrônico, das listas de discussão, dos fóruns, dos "colaboratórios", do trabalho coletivo assistido por computador etc. (que deve muito aos pesquisadores das áreas de ciência da informação e informática) reintroduziu a dimensão interativa eliminada pelos procedimentos autoritários.

\section{III - O PRINCÍPIO CONSUMERISTA (E-USUÁRIO)}

O objetivo final de um produto de informação, de um serviço de informação e de um sistema de informação deve ser pensado em função dos usos que são feitos da informação e dos efeitos resultantes desse uso nas atividades dos usuários. A função mais importante do produto, do sistema, é, portanto, a maneira como a informação modifica a condução dessas atividades. Mas esta visão centrada no usuário envolve um novo taylorismo/fordismo. Com efeito, enquanto este último parece desaparecer no setor secundário, industrial, desenvolve-se no setor terciário, o de serviços. Surgem novas formas de pressão sobre os trabalhadores e trabalhadoras, sobretudo ligadas à exigência do usuário, do cliente. Paradoxalmente, nas atividades que mantêm contato com os usuários, encontram-se as formas de trabalho mais duras, as mais próximas do taylorismo, mesmo que estas atividades compreendam um aspecto de relacionamento.

Com a ajuda do neoliberalismo, já que o uso da informação e dos serviços de informação não rima necessariamente com gratuidade, surgiram, então, as figuras do cliente e do consumidor:

- no setor público, contata-se a comercialização de produtos culturais. A Biblioteca Nacional da França cobra um "direito de entrada". O direito de empréstimo foi imposto, não sem desonestidade, pelo editores às bibliotecas públicas.

- no setor privado, são feitas explorações sistemáticas para acompanhar as práticas dos usuários de sites da Web 
e para identificar os tipos de comportamento desses usuários, tendo por objetivo converter um visitante em consumidor, o e-cliente.

\section{IV - O PRINCÍPIO MÉTRICO (É-METRIA)}

Existem, na área de ciência da informação, regularidades, distribuições e relações mensuráveis, universais. Mas, só recentemente, o corpo desses conhecimentos matemáticos foi reunido e tiveram início aplicações dos setores culturais aos setores comerciais de informação, fazendo surgir a infometria e as suas correlatas: a bibliometria, a museometria, a mídiametria, a cientometria e a webometria.

Dessa maneira, atualmente, no setor cultural, educacional e de pesquisa, uma boa gestão de serviços públicos necessita cada vez mais da utilização de uma larga gama de ferramentas de gestão adaptadas aos contextos culturais, educativos, científicos e também às dimensões e características do serviço. São ferramentas de análise de necessidades de informação da comunidade atendida, ferramentas de acompanhamento e de avaliação e ferramentas de medição de performance. Estas ferramentas possibilitam à organização dispor de um conjunto de indicadores de desempenho.

No outro extremo, a abordagem comercial, particularmente invasora na Internet e nas mídias, audiovisuais, entre outras, conduz à realização de análises estatísticas elaboradas da "relação cliente" (Customer Relationship Management (CRM)) e da audiência: audiência por hora, data (dia, semana, mês), número de sessões, de máquinas, de páginas visitadas, de cliques etc.

Mas, por falta de unidades de medida coerentes, de ferramentas confiáveis e de métodos testados, torna-se difícil conhecer, por exemplo, as cifras reais de consultas a sites, os valores precisos de mudanças sociodemográficas e socioprofissionais da população atendida pela unidade de informação etc.

Além disso, devemos ter cuidado com o poder de fascinação que os despretenciosos números e cifras possuem nas organizações. Diante da complexidade dessas organizações, reduzir os julgamentos a algumas cifras responde a enormes expectativas. A linguagem secreta da estatística, tão atrativa em uma sociedade que convive com muitos acontecimentos e cifras, pode ser empregada para fazer sensacionalismo, para ampliar os resultados, ou para simplificar ao extremo: o primeiro site Web! O primeiro livro! Os dez mais artigos científicos! etc.

\section{V - O PRINCÍPIO ELETRODIGITAL (E-DIGITAL)}

Em tecnologia da informação, é cada vez maior o espaço do suporte eletrônico (o elétron), encorajando, por sinal, certos tecnófilos a vislumbrar o fim do suporte em papel. É preciso admitir que o desempenho da eletrônica digital, conjugado ao da optoeletrônica (o fóton), é particularmente impressionante. Ele conduz a uma eliminação vertiginosa do espaço e do tempo.

Encontra-se aí a origem do slogan Totalmente eletrônico, totalmente digital e do princípio diretor eletrodigital. Isto faz lembrar um slogan do mesmo tipo lançado, há 30 anos, pelos partidários da eletricidade nuclear: Totalmente elétrico, totalmente nuclear. Isso significava dizer que em uma casa tudo funcionaria à eletricidade, que as fontes alternativas de energia (carbono, gás, petróleo) seriam abandonadas e que a produção de eletricidade só poderia ser feita nas centrais nucleares. Sabemos que esta predição não se realizou.

Da mesma maneira, os projetos de cabeamento em fibra ótica lançados pelo slogan Totalmente ótico, totalmente digital não surtiram efeito. $O$ cabo coaxial não foi abandonado, e o hertziano reapareceu. Podemos, portanto, vislumbrar futuros não digitais, mas quânticos, ou ainda outros futuros digitais, não-binários, mas ternários, quaternários, ...n-ários ou mesmo um retorno ao cabo analógico.

\section{CONCLUSÃO}

Existem hoje cinco princípios diretores na ciência da informação eletrônica. São estes princípios que nos parecem atualmente orientar fortemente o pensamento e as práticas profissionais do setor, quer sejam acadêmicas ou industriais. Como em todas as ciências, uma estrutura intelectual está sendo mobilizada. Mostramos, em nossa obra Ciência da Informação, que esta ciência só tem sentido no contexto da construção de conhecimentos científicos, da produção de informações científicas e da comunicação e uso dessas informações. Constitutivos dessa estrutura, existem fortes princípios, e estes caracterizam paradigmas. Adotados por uns, rechaçados ou desconsiderados por outros, eles demoram a se estabilizarem. Além disso, fatores sociológicos, econômicos e políticos determinantes afetam estes princípios, e o desencadeamento tecnológico, apesar de aceito, provoca forte instabilidade.

São eles, porém, o devir e, como acreditamos, são o futuro de nossa ciência.

Então, bom 100ำ aniversário! 
